\title{
Polyphenols and brain health
}

\author{
David Vauzour* \\ Norwich Medical School, James Watson Road, University of East Anglia, Norwich Research Park, Norwich NR4 7UQ, UK
}

Received 13 February 2017 - Accepted 24 February 2017

\begin{abstract}
Accumulating evidence suggests that diet and lifestyle can play an important role in delaying the onset or halting the progression of age-related health disorders and to improve cognitive function. A growing number of dietary intervention studies in humans and animals and in particular those using polyphenol-rich diets have been proposed to exert a multiplicity of neuroprotective actions within the brain, including a potential to protect neurons against injury induced by neurotoxins, an ability to suppress neuroinflammation and a potential to promote memory, learning, and cognitive functions. These effects appear to be underpinned by two common processes. First, they are capable of interactions with critical protein and lipid kinase signalling cascades in the brain, leading to an inhibition of apoptosis triggered by neurotoxic species and to a promotion of neuronal survival and synaptic plasticity. Second, they induce beneficial effects on the vascular system, leading to changes in cerebrovascular blood flow capable of causing enhance vascularisation and neurogenesis, two events important in the maintenance of cognitive performances. Together, these processes act to maintain brain homeostasis and play important roles in neuronal stress adaptation and thus polyphenols might have the potential to prevent the progression of neurodegenerative pathologies.
\end{abstract}

Keywords: flavonoids / ageing / neuroinflammation / cognition / signalling pathways

\section{Introduction}

Over the last decade, a vast and growing research literature has been focusing on the potential of dietary polyphenols for aiding preservation of cognitive function during ageing while reducing risk for neurodegenerative disorders (Letenneur et al., 2007; Nurk et al., 2009; Gu et al., 2010; Nooyens et al., 2011; Solfrizzi et al., 2011; Loef and Walach, 2012; Vauzour, 2012). For example, the regular dietary intake of polyphenol-rich foods and/or beverages has been associated with $50 \%$ reduction in the risk of dementia (Commenges et al., 2000), a preservation of cognitive performance with ageing (Morris et al., 2006; Letenneur et al., 2007), a delay in the onset of Alzheimer's disease (Dai et al., 2006; Pasinetti et al., 2015) and a reduction in the risk of developing Parkinson's disease (Checkoway et al., 2002; Chen et al., 2015). It is now widely accepted that the biological actions of polyphenols within the nervous system are not solely due to their classical hydrogen donating antioxidant activity (Williams et al., 2004). Rather, it has become evident that polyphenols are more likely to exert beneficial effects in the brain (at low and physiological concentrations) by preventing neurodegeneration, inhibiting neuroinflammation and reducing age-related cognitive decline (Vauzour et al., 2008; Vauzour, 2012). In particular,

\footnotetext{
* Corresponding author: D. Vauzour@uea.ac.uk
}

these interactions include an ability to activate signalling pathways, critical in controlling synaptic plasticity and a potential to induce vascular effects capable of causing new nerve cell growth in the hippocampus (Spencer et al., 2009; Vauzour, 2012). This review will describe the potential of polyphenols to modulate brain functions and will summarise the possible mechanisms implicated in such beneficial effects.

\section{Polyphenols structure and occurrence}

Polyphenols are a group of naturally occurring phytochemicals which are present in high amounts in fruits and vegetables. These compounds are characterised by the presence of multiple hydroxyl groups on aromatic rings and are divided into two main categories, the flavonoids and nonflavonoids, based on the number of phenol rings and the way in which these rings interact.

Flavonoids have a C6-C3-C6 structure and share a common feature which consist of two aromatic carbon rings, benzopyran ( $\mathrm{A}$ and $\mathrm{C}$ rings) and benzene ( $\mathrm{B}$ ring), and may be divided in various subgroups based on the degree of the oxidation of the C-ring, the hydroxylation pattern of the ring structure and the substitution of the 3-position. The main dietary groups of flavonoids are: (1) flavones (e.g. apigenin, luteolin), which are found in parsley and celery; (2) flavonols (e.g. kaempferol, quercetin), which are found in onions, leeks, broccoli; 
(3) isoflavones (e.g. daidzein, genistein), which are mainly found in soy and soy products; (4) flavanones/flavanonols (e.g. hesperetin, naringenin/astilbin, engeletin), which are mainly found in citrus fruit, herbs (oregano) and wine; (5) flavanols (e.g. $(+)$-catechin, (-)-epicatechin, epigallocatechin, epigallocatechin gallate (EGCG)), which are abundant in green tea, red wine, chocolate; and (6) anthocyanidins (e.g. pelargonidin, cyanidin, malvidin), whose sources include red wine and berry fruits.

The non-flavonoid group may be separated into two different classes: (1) the phenolic acids, including the hydroxybenzoic acids $(\mathrm{C} 1-\mathrm{C} 3$ skeleton; i.e. protocatechuic and gallic acids) and hydroxycinnamic acids (C3-C6 skeleton; i.e. caffeic and chlorogenic acids) together found in many fruits and vegetables; (2) the stilbenes (C6-C2-C6 structure; i.e. resveratrol) found in grapes, wine, peanuts. For further details of the structures and occurrence of these compounds readers should consult Rodriguez-Mateos (Rodriguez-Mateos et al., 2014), along with the ever expanding Phenol-Explorer database which includes comprehensive information of the polyphenol content of foods (Neveu et al., 2010).

\section{Effects of polyphenols on age-related cognitive decline and neurodegenerative disorders}

Ageing is a normal and inevitable process in life. It progresses more or less rapidly depending on our lifestyle habits (sedentary, western-type diet, alcohol, and smoking). The normal brain ageing affects the frontal and temporal lobes more than the parietal and occipital lobes (Bentourkia et al., 2000) and is characterised by a progressive decline in cognitive abilities mainly in hippocampal circuit, including the dentate gyrus, and the prefrontal cortex (for long-term memory) (Morrison and Baxter, 2012). In addition, past and recent research shows that the ageing process causes declines in both motor and cognitive functions even in absence of neurodegenerative disease, in both animals (Ingram et al., 1994; Shukitt-Hale et al., 1998) and humans (West, 1996; Muir, 1997). Alterations in cognition appear to occur primarily in secondary memory systems, such as memory performance (e.g. delayed recall of a story presented once) (Dixon et al., 2004), processing, working memory (Corona et al., 2013), and executive function (Siedlecki et al., 2005). Increased fruits and vegetables intake has been associated with improved cognitive function (Sofi et al., 2010; Tangney et al., 2011; Lamport et al., 2016), and may be in large part attributable to intake of polyphenols (BarbergerGateau et al., 2007). In particular, increased consumption of polyphenols was positively associated with better language and episodic memory in middle-aged healthy adults (45-60 years old) (Kesse-Guyot et al., 2012) and with a greater cognitive performance at baseline and less decline across the follow-up assessments in non-demented adults aged 70 and over (Letenneur et al., 2007). Similarly, greater intakes of blueberries and strawberries anthocyanins were associated with slower rates of cognitive decline in non-demented adults aged 70 and over (Devore et al., 2012). Blueberry appears to have a pronounced effect on short-term (Ramirez et al., 2005) and long-term memory (Casadesus et al., 2004), and animal studies have provided further evidence for the efficacy of blueberries (Williams et al., 2008; Rendeiro et al., 2012), indicating that improvements in spatial memory may emerge within 3 weeks, the equivalent of about 3 years in humans. In addition, pure (-)-epicatechin $(500 \mu \mathrm{g} / \mathrm{g})$ was observed to enhance the retention of spatial memory in C57BL/6 mice (8-10 week old), especially when combined with exercise (van Praag et al., 2007), similarly to green tea catechins $(0.025-0.1 \% \mathrm{w} / \mathrm{v})$ (Li et al., 2009a). The mechanisms seem to involve an indirect action on the dentate gyrus (DG) (Casadesus et al., 2004; Burke and Barnes, 2006; Rendeiro et al., 2012; Rendeiro et al., 2013). Such link between hippocampal neurogenesis, cognitive performance and ageing may represent a potential mechanism by which polyphenol-derived foods may improve memory (Stangl and Thuret, 2009). However, although epidemiological and pre-clinical studies have lent some support to the neurocognitive potential of polyphenols, human intervention results are less clear (Scholey et al., 2010; Field et al., 2011) and further work is still necessary to confirm these preliminary observations (Vauzour et al., 2016).

In addition to age-related cognitive decline, epidemiological, preclinical and clinical studies have also explored the neuroprotective effect of natural compounds in clinical conditions (Commenges et al., 2000; Letenneur et al., 2007; Pasinetti, 2015; Pasinetti et al., 2015). Verbal learning was improved in older adults with mild cognitive impairment (MCI) after consumption of Concord grape juice (Krikorian et al., 2010a), blueberry juice (Krikorian et al., 2010b) and flavanols (Desideri et al., 2012). Although the exact mechanisms underlying these improvements are not clear, it has been suggested that polyphenols may delay the initiation of and/or slow the progression of Alzheimer's Disease (AD)-like pathology, including a potential to inhibit neuronal apoptosis triggered by neurotoxic species (e.g. oxidative stress and neuroinflammation) (Vauzour et al., 2007a; Mori et al., 2012; Cox et al., 2015). Polyphenols can reduce amyloid-beta $(\mathrm{A} \beta)$ plaque pathology (Hirohata et al., 2007; Amit et al., 2008; Ehrnhoefer et al., 2008; Ono et al., 2008; Wang et al., 2014), and therefore they could have utility in AD beyond anti-A $\beta$ processing (Wang et al., 2015). For example, oral administration of epigallocatechin-3-gallate (EGCG, $50 \mathrm{mg} / \mathrm{kg}$ ) for 6 months in mice which over-express the Swedish mutation of APP (APPsw; 8 months old), reduced A $\beta$ pathology and improved cognition (Rezai-Zadeh et al., 2008). Long term green tea catechin administration $(0.05-0.1 \% \mathrm{w} / \mathrm{v})$ also improved spatial learning and memory in senescence prone mice, by decreasing $A \beta_{1-42}$ oligomers and upregulating synaptic plasticity-related proteins in the hippocampus (Li et al., 2009b). However, a recent investigation reported a cognitive-enhancing effect of a polyphenol-rich without changes in either A $\beta$ or Tau pathologies, therefore suggesting that polyphenols-rich extracts may prevent memory impairment associated with age-related diseases, without significant effects on classical AD neuropathology (Dal-Pan et al., 2017). Further work is therefore required to fully apraise whether polyphenols have efficacy in individuals affected by dementia.

\section{Cellular and molecular interactions underlying the cognitive effects of polyphenols}

It has generally been assumed that the health benefits of polyphenols were linked to their capacity to directly scavenge 
free radicals and other nitrogen species in vitro (Pannala et al., 1997; Visioli et al., 1998; Russo et al., 2000; Halliwell, 2006). However, the concentrations at which they exert such antioxidant activity is unlikely to be easily achieved in vivo as many polyphenols have very limited bioavailability and are extensively metabolised in the gut and the liver (RodriguezMateos et al., 2014). Instead, recent findings have suggested that in lower amounts, typical of those attained in the diet, polyphenols may exert pharmacological activity within the cells with mechanisms that go beyond the classic antioxidant scavenging mechanisms (Williams et al., 2004; Vauzour et al., 2010). In particular, polyphenols are capable of modulating intracellular signalling cascades (Spencer et al., 2009; Vauzour et al., 2010; Kuo et al., 2015), gene expression and interactions with mitochondria (Schroeter et al., 2001; Schroeter et al., 2007; Vauzour et al., 2007b; Mandel et al., 2008). By affecting such pathways, they have the potential to induce new protein synthesis in neurons and thus an ability to induce morphological changes, which have a direct influence on memory acquisition, consolidation and storage. Alternatively, their well established effects on the vascular system may also induce increases in cerebral blood flow capable of impacting on acute cognitive performance, or may lead to an increase hippocampal vascularisation capable of inducing new neuronal growth.

\subsection{Polyphenols affect signalling cascades involved in synaptic plasticity maintenance}

The activation of various signalling pathways have been linked with the control of synaptic plasticity and memory (Spencer et al., 2009) which all converge to the cAMP-response element-binding protein (CREB), a transcription factor which binds to the promoter regions of many genes associated with synapse re-modelling, increases in neuronal spine density and synaptic plasticity (Impey et al., 2004; Barco et al., 2006). Such interactions may lead to improvements in memory through induction of synapse growth and connectivity, increases in dendritic spine density and the functional integration of old and new neurons. As such, nutrients which interact with these pathways may also be capable of reducing the neurodegenerative injury associated with major brain diseases.

There is much evidence to support the actions of polyphenols on the ERK pathway (Schroeter et al., 2007; Vauzour et al., 2007b), which often leads to the activation of CREB (Corona et al., 2013), a transcription factor considered to be critical in the induction of long-lasting changes in synaptic plasticity and memory (Bourtchuladze et al., 1994; Impey et al., 1998). Indeed, CREB activation regulates the expression of a number of important genes, including the brain derived neurotrophic factor (BDNF), thus playing a pivotal role in controlling neuronal survival, and synaptic function in the adult central nervous system (Finkbeiner, 2000; Tully et al., 2003). Regulation of BDNF is of particular interest as it is linked with the control of synaptic plasticity and longterm memory (Finkbeiner et al., 1997; Carito et al., 2014). Additionally, interactions are suggested to exist between BDNF, age-related cognitive decline and other cognitivebehavioural disorders. For example, age-related hippocampal atrophy is associated with memory-impairment, and therefore it is hypothesised that lower BDNF levels partly mediate this physiological change (Erickson et al., 2012). Recent studies have shown that spatial memory performance in rats supplemented with blueberry, correlates well with the activation of CREB and with increases of BDNF in the hippocampus (Ramirez et al., 2005; Wang et al., 2011). In agreement with these observation, two recently conducted clinical trials reported concurrent changes in serum BDNF levels and global cognition scores following high polyphenol consumption, therefore suggesting a role for BDNF in polyphenol-induced cognitive improvements (Neshatdoust et al., 2016). As well as effects on the ERK/CREB/BDNF axis, polyphenols are also known to modulate the activity of Akt (also known as PKB), triggering the increased translation of specific mRNA subpopulations (Vlahos et al., 1994), including the activity-regulated cytoskeletal-associated protein (Arc/Arg3.1) (Ramirez et al., 2005), facilitating changes in synaptic strength, and the induction of morphological changes in dendritic spine density and outgrowth (Waltereit et al., 2001).

\subsection{Polyphenols mitigate neuroinflammation}

Growing evidence is also suggestive that cognitive decline is in part mediated by an increase in neuroinflammatory stimuli linked to over-production of microglia-derived pro-inflammatory cytokines and reactive oxygen species. For example, increased neuroinflammation and oxidative stress can perturb the proper function of brain neurons, they can impede the efficiency of long term potentiation required for new memory formation, they can amplify the production and potentiate the effects of the $A \beta$ protein. Since evidence emerged that non-steroidal anti-inflammatory drugs may be effective in delaying the onset of neurodegenerative disorders (Moore and O'Banion, 2002), there has been much interest in the development of new drugs capable of preventing neuroinflammatory mediated brain injury. Over the last years, efforts have been made at investigating the effect polyphenols on neuroinflammation. Although not exhaustive, the main antiinflammatory properties of polyphenols may be summarised by (1) a capacity to downregulate the activity of proinflammatory transcription factors such as NF- $\mathrm{B}, \mathrm{Nrf2}$ or STAT through their influences on a number of glial and neuronal signalling pathways, (2) an inhibitory role on the release of cytokines, such as interleukin IL- $1 \beta$ and TNF- $\alpha$, from primed microglia, (3) an inhibitory action against the production of $\mathrm{NO}$ and PGE2 in response to microglia activation, (4) an ability to inhibit the activation of NADPH oxidase and subsequent ROS generation in activated glia, and (5) an inhibitory action against microglia priming through toll-like receptors (TLR) activation (Gonzalez-Gallego et al., 2010; Vauzour, 2014). For example, fisetin (0.05\%, 6 months) reduced the protein expression of inflammatory markers in huAPPswe/PS1 $\Delta$ E9 transgenic mice in an ERK-p25-mediated pathway without affecting the mRNA expression of NF-кB1 (Currais et al., 2014). Similarly, kaempferol-3-O-rutinoside $(10 \mathrm{mg} / \mathrm{kg})$ and kaempferol-3-O-glucoside $(7.5 \mathrm{mg} / \mathrm{kg})$ reduced the neuroinflammatory response by inhibiting signal transducer and activator of transcription 3 (STAT3) and $\mathrm{NF}-\kappa \mathrm{B}$ following an ischemic brain injury in rats (Yu et al., 2013). In addition, intervention trial with an anthocyanin 
extract from blueberries $(300 \mathrm{mg} / \mathrm{d}$ for 3 weeks $)$ significantly reduced the plasma concentration of NF-kB-related proinflammatory cytokines and chemokines (IL-4, IL-13, IL-8 and IFN- $\alpha$ ) in a group of 120 men and women aged 40-74 years (Karlsen et al., 2007). However, no significant effect has been observed in plasma levels of CRP or ICAM-1 among healthy volunteers consuming diets rich or poor in berries and apple for 6 weeks (Freese et al., 2004). Equally, a 4-week administration of quercetin significantly increased plasma levels of quercetin, but did not alter ex vivo LPS-induced TNF$\alpha$ levels (Boots et al., 2008). Although work carried out in cells or animal models have lent some support to the antiinflammatory effect of polyphenols, the inconsistent outcome of various clinical trials on the preventive anti-inflammatory effect of polyphenols reinforces the necessity for more prospective randomised trials with larger sample sizes, longer follow-up in both healthy volunteers and in clinical conditions.

\subsection{Polyphenols-induced change in (cerebro)vascular functions}

Compelling evidence derived from human clinical studies is suggesting that polyphenols can positively affect peripheral (Hooper et al., 2008; Kay et al., 2012) and cerebrovascular blood flow (Schroeter et al., 2006; Heiss et al., 2007; Sorond et al., 2008; Jagla and Pechanova, 2015), which may be an indirect effective mechanism by these molecules could impact on brain health and cognition. For example, a high-flavanone citrus juice $(70.5 \mathrm{mg} / 500 \mathrm{ml})$ was associated with significantly increased regional perfusion in the inferior and middle right frontal gyrus at $2 \mathrm{~h}$ relative to baseline and the control drink in young healthy volunteers (Lamport et al., 2016). Similarly, significant increases in regional perfusion across the brain were observed following consumption of a high flavanol drink relative to the low flavanol drink, particularly in the anterior cingulate cortex and the central opercular cortex of the parietal lobe (Lamport et al., 2015). Longer-term interventions (3 months) also with cocoa flavanols in aged subjects revealed increases in cerebral blood volume (fMRI) in the DG of the hippocampus, which was highly correlated with improvements in performance in the DG-dependent Modified Benton task (Brickman et al., 2014). Furthermore, ageing is known to impair vascularisation, endothelial function and decreases endothelial progenitor cell recruitment, which could adversely affect neurogenesis. Therefore, the influence of dietary agents on angiogenesis (van Praag et al., 2007) and the production of vascular derived factors are also likely to influence neurogenesis (Casadesus et al., 2004). Ultimately, the effects of polyphenols on the hippocampus are likely to be very dependent on local concentration and, at present, it remains unclear whether polyphenols induce global changes in hippocampal (and other brain region) morphology/function, or are capable of inducing changes within specific hippocampal sub-regions. However, if such effects prove possible, then diet would have the potential to not only slow the progression of neurodegeneration and cognitive decline, but also to potentially reverse disease and cognitive impairment via the re-population of neurons in the hippocampus. In summary, despite clear evidence regarding the acute vascular effects of flavonoids shown in humans (Macready et al., 2010) and medium-term changes in synaptic plasticity markers demonstrated in animal studies (Spencer, 2009), the basic mechanisms of action of polyphenols in humans remains unclear, due to a lack of precise causative/mechanistic data. Future work should strive to determine the mechanistic basis of polyphenol-induced improvements in cognitive function by investigating the degree to which peripheral- and cerebral blood flow induced by polyphenol metabolites plays in determining improvements in human cognitive performance, in particular attention and episodic memory.

\section{Conclusion}

Decline on cognitive abilities with age occurs in healthy individuals and spreads through adult lifespan. The mechanisms contributing to normal aging, including oxidative stress, neuroinflammation and vascular dysfunction are the same than those contributing to the development of neurological diseases. However, in pathological conditions these mechanisms are exacerbated and are triggered by different factors which might be genetic or environmental. The consumption of polyphenolrich foods throughout life holds a potential to limit neurodegeneration and prevent or reverse age-dependent deteriorations in cognitive performance. However, the therapeutic and pharmacological potential of these natural compounds still remains to be fully translated in humans and in clinical conditions. The challenge ahead therefore, is to proceed cautiously until rigorous randomized controlled clinical trials have been undertaken to determine empirically whether polyphenols and/or their in vivo metabolites have efficacy in individuals affected by dementia and other neurodegenerative conditions.

\section{Abbreviations}

\begin{tabular}{|c|c|}
\hline $\mathrm{AD}$ & Alzheimer's disease \\
\hline APP & amyloid precursor protein \\
\hline Arc/Arg3.1 & $\begin{array}{l}\text { activity-regulated cytoskeleton-associated protein } \\
\text { (also known as Arg3.1) }\end{array}$ \\
\hline$A \beta$ & amyloid beta \\
\hline BDNF & brain derived neurotrophic factor \\
\hline CREB & c-AMP-response element binding protein \\
\hline CRP & $\mathrm{C}$ reactive protein \\
\hline DG & dentate gyrus \\
\hline EGCG & epigallocatechin-3-gallate \\
\hline ERK & extracellular signal-regulated kinases \\
\hline fMRI & functional magnetic resonance imaging \\
\hline ICAM-1 & Intercellular Adhesion Molecule 1 \\
\hline IL-1b & interleukin 1 beta \\
\hline LPS & lipopolysaccharide \\
\hline $\mathrm{NF}-\mathrm{Kb}$ & nuclear factor- $\mathrm{kB}$ \\
\hline NO & nitric oxide \\
\hline Nox & NADPH oxidase \\
\hline Nrf2 & nuclear factor erythroid-related factor 2 \\
\hline PGE2 & prostaglandin E2 \\
\hline ROS & reactive oxygen species \\
\hline STAT3 & signal transducer and activator of transcription 3 \\
\hline TLR & toll-like receptor \\
\hline $\mathrm{TNFa}$ & tumour necrosis factor alpha \\
\hline
\end{tabular}




\section{References}

Amit T, Avramovich-Tirosh Y, Youdim MB, Mandel S. 2008. Targeting multiple Alzheimer's disease etiologies with multimodal neuroprotective and neurorestorative iron chelators. FASEB J 22: 1296-1305.

Barberger-Gateau P, Raffaitin C, Letenneur L, et al. 2007. Dietary patterns and risk of dementia: the Three-City cohort study. Neurology 69: 1921-1930.

Barco A, Bailey CH, Kandel ER. 2006. Common molecular mechanisms in explicit and implicit memory. $J$ Neurochem 97 : $1520-1533$.

Bentourkia M, Bol A, Ivanoiu A, et al. 2000. Comparison of regional cerebral blood flow and glucose metabolism in the normal brain: effect of aging. J Neurol Sci 181: 19-28.

Boots AW, Wilms LC, Swennen EL, Kleinjans JC, Bast A, Haenen GR. 2008. In vitro and ex vivo anti-inflammatory activity of quercetin in healthy volunteers. Nutrition 24: 703-710.

Bourtchuladze R, Frenguelli B, Blendy J, Cioffi D, Schutz G, Silva AJ. 1994. Deficient long-term memory in mice with a targeted mutation of the cAMP-responsive element-binding protein. Cell 79: $59-68$

Brickman AM, Khan UA, Provenzano FA, et al. 2014. Enhancing dentate gyrus function with dietary flavanols improves cognition in older adults. Nat Neurosci 17: 1798-1803.

Burke SN, Barnes CA. 2006. Neural plasticity in the ageing brain. Nat Rev Neurosci 7: 30-40.

Carito V, Venditti A, Bianco A, et al. 2014. Effects of olive leaf polyphenols on male mouse brain NGF, BDNF and their receptors TrkA, TrkB and p75. Nat Prod Res 28: 1970-1984.

Casadesus G, Shukitt-Hale B, Stellwagen HM, et al. 2004. Modulation of hippocampal plasticity and cognitive behavior by short-term blueberry supplementation in aged rats. Nutr Neurosci 7: 309-316.

Checkoway H, Powers K, Smith-Weller T, Franklin GM, Longstreth Jr. WT, Swanson PD. 2002. Parkinson's disease risks associated with cigarette smoking, alcohol consumption, and caffeine intake. Am J Epidemiol 155: 732-738.

Chen M, Wang T, Yue F, et al. 2015. Tea polyphenols alleviate motor impairments, dopaminergic neuronal injury, and cerebral alphasynuclein aggregation in MPTP-intoxicated parkinsonian monkeys. Neuroscience 286: 383-392.

Commenges D, Scotet V, Renaud S, Jacqmin-Gadda H, BarbergerGateau P, Dartigues JF. 2000. Intake of flavonoids and risk of dementia. Eur J Epidemiol 16: 357-363.

Corona G, Vauzour D, Hercelin J, Williams CM, Spencer JP. 2013. Phenolic acid intake, delivered via moderate champagne wine consumption, improves spatial working memory via the modulation of hippocampal and cortical protein expression/ activation. Antioxid Redox Signal 19: 1676-1689.

Cox CJ, Choudhry F, Peacey E, et al. 2015. Dietary (-)-epicatechin as a potent inhibitor of betagamma-secretase amyloid precursor protein processing. Neurobiol Aging 36: 178-187.

Currais A, Prior M, Dargusch R, et al. 2014. Modulation of p25 and inflammatory pathways by fisetin maintains cognitive function in Alzheimer's disease transgenic mice. Aging Cell 13: 379-390.

Dai Q, Borenstein AR, Wu Y, Jackson JC, Larson EB. 2006. Fruit and vegetable juices and Alzheimer's disease: the Kame Project. Am J Med 119: 751-759.

Dal-Pan A, Dudonne S, Bourassa P, et al. 2017. Cognitive-enhancing effects of a polyphenols-rich extract from fruits without changes in neuropathology in an animal model of Alzheimer's disease. $J$ Alzheimers Dis 55: 115-135.
Desideri G, Kwik-Uribe C, Grassi D, et al. 2012. Benefits in cognitive function, blood pressure, and insulin resistance through cocoa flavanol consumption in elderly subjects with mild cognitive impairment: the Cocoa, Cognition, and Aging (CoCoA) study. Hypertension 60: 794-801.

Devore EE, Kang JH, Breteler MM, Grodstein F. 2012. Dietary intakes of berries and flavonoids in relation to cognitive decline. Ann Neurol 72(1): 135-143.

Dixon RA, Wahlin A, Maitland SB, Hultsch DF, Hertzog C, Backman L. 2004. Episodic memory change in late adulthood: generalizability across samples and performance indices. Mem Cognit 32: 768-778.

Ehrnhoefer DE, Bieschke J, Boeddrich A, et al. 2008. EGCG redirects amyloidogenic polypeptides into unstructured, off-pathway oligomers. Nat Struct Mol Biol 15: 558-566.

Erickson KI, Miller DL, Roecklein KA. 2012. The aging hippocampus: interactions between exercise, depression, and BDNF. Neuroscientist 18: 82-97.

Field DT, Williams CM, Butler LT. 2011. Consumption of cocoa flavanols results in an acute improvement in visual and cognitive functions. Physiol Behav 103: 255-260.

Finkbeiner S. 2000. CREB couples neurotrophin signals to survival messages. Neuron 25: 11-14.

Finkbeiner S, Tavazoie SF, Maloratsky A, Jacobs KM, Harris KM, Greenberg ME. 1997. CREB: a major mediator of neuronal neurotrophin responses. Neuron 19: 1031-1047.

Freese R, Vaarala O, Turpeinen AM, Mutanen M. 2004. No difference in platelet activation or inflammation markers after diets rich or poor in vegetables, berries and apple in healthy subjects. Eur $J$ Nutr 43: 175-182.

Gonzalez-Gallego J, Garcia-Mediavilla MV, Sanchez-Campos S, Tunon MJ. 2010. Fruit polyphenols, immunity and inflammation. Br J Nutr 104 (Suppl 3): S15-S27.

$\mathrm{Gu}$ Y, Nieves JW, Stern Y, Luchsinger JA, Scarmeas N. 2010. Food combination and Alzheimer disease risk: a protective diet. Arch Neurol 67: 699-706.

Halliwell B. 2006. Oxidative stress and neurodegeneration: where are we now? J Neurochem 97: 1634-1658.

Heiss C, Finis D, Kleinbongard P, et al. 2007. Sustained increase in flow-mediated dilation after daily intake of high-flavanol cocoa drink over 1 week. J Cardiovasc Pharmacol 49: 74-80.

Hirohata M, Hasegawa K, Tsutsumi-Yasuhara S, et al. 2007. The antiamyloidogenic effect is exerted against Alzheimer's beta-amyloid fibrils in vitro by preferential and reversible binding of flavonoids to the amyloid fibril structure. Biochemistry 46: 1888-1899.

Hooper L, Kroon PA, Rimm EB, et al. 2008. Flavonoids, flavonoidrich foods, and cardiovascular risk: a meta-analysis of randomized controlled trials. Am J Clin Nutr 88: 38-50.

Impey S, Smith DM, Obrietan K, Donahue R, Wade C, Storm DR. 1998. Stimulation of cAMP response element (CRE)mediated transcription during contextual learning. Nat Neurosci 1: 595-601.

Impey S, McCorkle SR, Cha-Molstad H, et al. 2004. Defining the CREB regulon: a genome-wide analysis of transcription factor regulatory regions. Cell 119: 1041-1054.

Ingram DK, Spangler EL, Iijima S, et al. 1994. New pharmacological strategies for cognitive enhancement using a rat model of agerelated memory impairment. Ann N Y Acad Sci 717: 16-32.

Jagla F, Pechanova O. 2015. Age-related cognitive impairment as a sign of geriatric neurocardiovascular interactions: may polyphenols play a protective role? Oxid Med Cell Longev 2015: 721514. 
Karlsen A, Retterstol L, Laake P, et al. 2007. Anthocyanins inhibit nuclear factor-kappaB activation in monocytes and reduce plasma concentrations of pro-inflammatory mediators in healthy adults. J Nutr 137: 1951-1954.

Kay CD, Hooper L, Kroon PA, Rimm EB, Cassidy A. 2012. Relative impact of flavonoid composition, dose and structure on vascular function: a systematic review of randomised controlled trials of flavonoid-rich food products. Mol Nutr Food Res 56: 1605-1616.

Kesse-Guyot E, Fezeu L, Andreeva VA, et al. 2012. Total and specific polyphenol intakes in midlife are associated with cognitive function measured 13 years later. J Nutr 142: 76-83.

Krikorian R, Nash TA, Shidler MD, Shukitt-Hale B, Joseph JA. 2010a. Concord grape juice supplementation improves memory function in older adults with mild cognitive impairment. Br J Nutr 103: 730-734.

Krikorian R, Shidler MD, Nash TA, et al. 2010b. Blueberry supplementation improves memory in older adults. J Agric Food Chem 58: 3996-4000.

Kuo PH, Lin CI, Chen YH, Chiu WC, Lin SH. 2015. A highcholesterol diet enriched with polyphenols from Oriental plums (Prunus salicina) improves cognitive function and lowers brain cholesterol levels and neurodegenerative-related protein expression in mice. Br J Nutr 113: 1550-1557.

Lamport DJ, Pal D, Moutsiana C, et al. 2015. The effect of flavanolrich cocoa on cerebral perfusion in healthy older adults during conscious resting state: a placebo controlled, crossover, acute trial. Psychopharmacology (Berl) 232: 3227-3234.

Lamport DJ, Pal D, Macready AL, et al. 2016. The effects of flavanone-rich citrus juice on cognitive function and cerebral blood flow: an acute, randomised, placebo-controlled cross-over trial in healthy, young adults. Br J Nutr 116: 2160-2168.

Letenneur L, Proust-Lima C, Le GA, Dartigues JF, Barberger-Gateau P. 2007. Flavonoid intake and cognitive decline over a 10-year period. Am J Epidemiol 165: 1364-1371.

Li Q, Zhao HF, Zhang ZF, et al. 2009a. Long-term administration of green tea catechins prevents age-related spatial learning and memory decline in C57BL/6 J mice by regulating hippocampal cyclic amp-response element binding protein signaling cascade. Neuroscience 159: 1208-1215.

Li Q, Zhao HF, Zhang HF, et al. 2009b. Long-term green tea catechin administration prevents spatial learning and memory impairment in senescence-accelerated mouse prone- 8 mice by decreasing Abeta1-42 oligomers and upregulating synaptic plasticity-related proteins in the hippocampus. Neuroscience 163: 741-749.

Loef M, Walach H. 2012. Fruit, vegetables and prevention of cognitive decline or dementia: a systematic review of cohort studies. J Nutr Health Aging 16: 626-630.

Macready AL, Butler LT, Kennedy OB, Ellis JA, Williams CM, Spencer JP. 2010. Cognitive tests used in chronic adult human randomised controlled trial micronutrient and phytochemical intervention studies. Nutr Res Rev 23: 200-229.

Mandel SA, Amit T, Kalfon L, Reznichenko L, Weinreb O, Youdim MB. 2008. Cell signaling pathways and iron chelation in the neurorestorative activity of green tea polyphenols: special reference to epigallocatechin gallate (EGCG). J Alzheimers Dis 15: 211-222.

Moore AH, O'Banion MK. 2002. Neuroinflammation and antiinflammatory therapy for Alzheimer's disease. Adv Drug Deliv Rev 54: 1627-1656.

Mori T, Rezai-Zadeh K, Koyama N, et al. 2012. Tannic acid is a natural beta-secretase inhibitor that prevents cognitive impairment and mitigates Alzheimer-like pathology in transgenic mice. J Biol Chem 287(9): 6912-6927.
Morris MC, Evans DA, Tangney CC, Bienias JL, Wilson RS. 2006. Associations of vegetable and fruit consumption with age-related cognitive change. Neurology 67: 1370-1376.

Morrison JH, Baxter MG. 2012. The ageing cortical synapse: hallmarks and implications for cognitive decline. Nat Rev Neurosci 13: 240-250.

Muir JL. 1997. Acetylcholine, aging, and Alzheimer's disease. Pharmacol Biochem Behav 56: 687-696.

Neshatdoust S, Saunders C, Castle SM, et al. 2016. High-flavonoid intake induces cognitive improvements linked to changes in serum brain-derived neurotrophic factor: two randomised, controlled trials. Nutr Healthy Aging 4: 81-93.

Neveu V, Perez-Jimenez J, Vos F, et al. 2010. Phenol-Explorer: an online comprehensive database on polyphenol contents in foods. Database (Oxford) 2010: bap024.

Nooyens AC, Bueno-de-Mesquita HB, van Boxtel MP, et al. 2011. Fruit and vegetable intake and cognitive decline in middle-aged men and women: the Doetinchem Cohort Study. Br J Nutr 106: 752-761.

Nurk E, Refsum H, Drevon CA, et al. 2009. Intake of flavonoid-rich wine, tea, and chocolate by elderly men and women is associated with better cognitive test performance. J Nutr 139: 120-127.

Ono K, Condron MM, Ho L, et al. 2008. Effects of grape seed-derived polyphenols on amyloid beta-protein self-assembly and cytotoxicity. J Biol Chem 283: 32176-32187.

Pannala AS, Rice-Evans CA, Halliwell B, Singh S. 1997. Inhibition of peroxynitrite-mediated tyrosine nitration by catechin polyphenols. Biochem Biophys Res Commun 232: 164-168.

Pasinetti GM. 2015. Novel role of red wine-derived polyphenols in the prevention of Alzheimer's disease dementia and brain pathology: experimental approaches and clinical implications. Planta Med 78(15): 1614-1619.

Pasinetti GM,Wang J, Ho L, Zhao W, Dubner L. 2015. Roles of resveratrol and other grape-derived polyphenols in Alzheimer's disease prevention and treatment. Biochim Biophys Acta 1852: 1202-1208.

Ramirez MR, Izquierdo I, do Carmo Bassols Raseira M, Zuanazzi JA, Barros D, Henriques AT. 2005. Effect of lyophilised Vaccinium berries on memory, anxiety and locomotion in adult rats. Pharmacol Res 52: 457-462.

Rendeiro C, Vauzour D, Kean RJ, et al. 2012. Blueberry supplementation induces spatial memory improvements and region-specific regulation of hippocampal BDNF mRNA expression in young rats. Psychopharmacology (Berl) 223: 319-330.

Rendeiro C, Vauzour D, Rattray M, et al. 2013. Dietary levels of pure flavonoids improve spatial memory performance and increase hippocampal brain-derived neurotrophic factor. PLoS One 8: e63535.

Rezai-Zadeh K, Arendash GW, Hou H, et al. 2008. Green tea epigallocatechin-3-gallate (EGCG) reduces beta-amyloid mediated cognitive impairment and modulates tau pathology in Alzheimer transgenic mice. Brain Res 1214: 177-187.

Rodriguez-Mateos A, Vauzour D, Krueger CG, et al. 2014. Bioavailability, bioactivity and impact on health of dietary flavonoids and related compounds: an update. Arch Toxicol 88: 1803-1853.

Russo A, Acquaviva R, Campisi A, et al. 2000. Bioflavonoids as antiradicals, antioxidants and DNA cleavage protectors. Cell Biol Toxicol 16: 91-98.

Scholey AB, French SJ, Morris PJ, Kennedy DO, Milne AL, Haskell CF. 2010. Consumption of cocoa flavanols results in acute improvements in mood and cognitive performance during sustained mental effort. J Psychopharmacol 24: 1505-1514. 
Schroeter H, Spencer JP, Rice-Evans C, Williams RJ. 2001. Flavonoids protect neurons from oxidized low-density-lipoprotein-induced apoptosis involving c-Jun N-terminal kinase (JNK), c-Jun and caspase-3. Biochem J 358: 547-557.

Schroeter H, Heiss C, Balzer J, et al. 2006. (-)-Epicatechin mediates beneficial effects of flavanol-rich cocoa on vascular function in humans. Proc Natl Acad Sci USA 103: 1024-1029.

Schroeter H, Bahia P, Spencer JPE, et al. 2007. (-)-Epicatechin stimulates ERK-dependent cyclic AMP response element activity and upregulates GLUR2 in cortical neurons. J Neurochem 101: 1596-1606.

Shukitt-Hale B, Mouzakis G, Joseph JA. 1998. Psychomotor and spatial memory performance in aging male Fischer 344 rats. Exp Gerontol 33: 615-624.

Siedlecki KL, Salthouse TA, Berish DE. 2005. Is there anything special about the aging of source memory? Psychol Aging 20: $19-32$.

Sofi F, Abbate R, Gensini GF, Casini A. 2010. Accruing evidence on benefits of adherence to the Mediterranean diet on health: an updated systematic review and meta-analysis. Am J Clin Nutr 92: 1189-1196.

Solfrizzi V, Panza F, Frisardi V, et al. 2011. Diet and Alzheimer's disease risk factors or prevention: the current evidence. Expert Rev Neurother 11: 677-708.

Sorond FA, Lipsitz LA, Hollenberg NK, Fisher ND. 2008. Cerebral blood flow response to flavanol-rich cocoa in healthy elderly humans. Neuropsychiatr Dis Treat 4: 433-440.

Spencer JP. 2009. The impact of flavonoids on memory: physiological and molecular considerations. Chem Soc Rev 38: 11521161.

Spencer JP, Vauzour D, Rendeiro C. 2009. Flavonoids and cognition: the molecular mechanisms underlying their behavioural effects. Arch Biochem Biophys 492: 1-9.

Stangl D, Thuret S. 2009. Impact of diet on adult hippocampal neurogenesis. Genes Nutr 4: 271-282.

Tangney CC, Kwasny MJ, Li H, Wilson RS, Evans DA, Morris MC. 2011. Adherence to a Mediterranean-type dietary pattern and cognitive decline in a community population. Am J Clin Nutr 93: 601-607.

Tully T, Bourtchouladze R, Scott R, Tallman J. 2003. Targeting the CREB pathway for memory enhancers. Nat Rev Drug Discov 2: 267-277.

van Praag H, Lucero MJ, Yeo GW, et al. 2007. Plant-derived flavanol $(-)$ epicatechin enhances angiogenesis and retention of spatial memory in mice. J Neurosci 27: 5869-5878.

Vauzour D. 2012. Dietary polyphenols as modulators of brain functions: biological actions and molecular mechanisms underpinning their beneficial effects. Oxid Med Cell Longev 2012: 914273.

Vauzour D. 2014. Effect of flavonoids on learning, memory and neurocognitive performance: relevance and potential implications for Alzheimer's disease pathophysiology. J Sci Food Agric 94: 1042-1056.
Vauzour D, Vafeiadou K, Corona G, Pollard SE, Tzounis X, Spencer JP. 2007a. Champagne wine polyphenols protect primary cortical neurons against peroxynitrite-induced injury. J Agric Food Chem 55: 2854-2860.

Vauzour D, VafeiAdou K, Rice-Evans C, Williams RJ, Spencer JP. 2007b. Activation of pro-survival Akt and ERK1/2 signalling pathways underlie the anti-apoptotic effects of flavanones in cortical neurons. J Neurochem 103: 1355-1367.

Vauzour D, Vafeiadou K, Rodriguez-Mateos A, Rendeiro C, Spencer JP. 2008. The neuroprotective potential of flavonoids: a multiplicity of effects. Genes Nutr 3: 115-126.

Vauzour D, Rodriguez-Mateos A, Corona G, Oruna-Concha MJ, Spencer JP. 2010. Polyphenols and human health: prevention of disease and mechanisms of action. Nutrients 2: 1106-1131.

Vauzour D, Camprubi-Robles M, Miquel-Kergoat S, et al. 2016. Nutrition for the ageing brain: towards evidence for an optimal diet. Ageing Res Rev, DOI: 10.1016/j.arr.2016.09.010.

Visioli F, Bellomo G, Galli C. 1998. Free radical-scavenging properties of olive oil polyphenols. Biochem Biophys Res Commun 247: 60-64.

Vlahos CJ, Matter WF, Hui KY, Brown RF. 1994. A specific inhibitor of phosphatidylinositol 3-kinase, 2-(4-morpholinyl)-8-phenyl4H-1-benzopyran-4-one (LY294002). J Biol Chem 269: 52415248.

Waltereit R, Dammermann B, Wulff P, et al. 2001. Arg3.1/Arc mRNA induction by $\mathrm{Ca}^{2+}$ and cAMP requires protein kinase $\mathrm{A}$ and mitogen-activated protein kinase/extracellular regulated kinase activation. J Neurosci 21: 5484-5493.

Wang D, Ho L, Faith J, et al. 2015. Role of intestinal microbiota in the generation of polyphenol-derived phenolic acid mediated attenuation of Alzheimer's disease beta-amyloid oligomerization. Mol Nutr Food Res 59: 1025-1040.

Wang J, Varghese M, Ono K, et al. 2014. Cocoa extracts reduce oligomerization of amyloid-beta: implications for cognitive improvement in Alzheimer's disease. J Alzheimers Dis 41: 643-650.

Wang W, Wang F, Yang YJ, et al. 2011. The flavonoid baicalein promotes NMDA receptor-dependent long-term potentiation and enhances memory. Br J Pharmacol 162: 1364-1379.

West RL. 1996. An application of prefrontal cortex function theory to cognitive aging. Psychol Bull 120: 272-292.

Williams CM, El Mohsen MA, Vauzour D, et al. 2008. Blueberryinduced changes in spatial working memory correlate with changes in hippocampal CREB phosphorylation and brainderived neurotrophic factor (BDNF) levels. Free Radic Biol Med 45: 295-305.

Williams RJ, Spencer JP, Rice-Evans C. 2004. Flavonoids: antioxidants or signalling molecules? Free Radic Biol Med 36: 838-849.

Yu L, Chen C, Wang LF, et al. 2013. Neuroprotective effect of kaempferol glycosides against brain injury and neuroinflammation by inhibiting the activation of NF-kappaB and STAT3 in transient focal stroke. PLoS One 8: e55839.

Cite this article as: Vauzour D. 2017. Polyphenols and brain health. OCL 24(2): A202. 